Trauma Surgery \& Acute Care Open

\title{
The TEAM (Trauma Evaluation and Management) course: medical student knowledge gains and retention in the USA versus Ghana
}

\author{
Allison E Berndtson, ${ }^{1}$ Martin Morna, ${ }^{2}$ Samuel Debrah, ${ }^{2}$ Raul Coimbra ${ }^{3}$
}

\begin{abstract}
'Department of Surgery, University of California San Diego Health System, San Diego, California, USA

2Department of Surgery, University of Cape Coast, Cape Coast, Ghana

${ }^{3}$ Department of General Surgery, Riverside University Health System Medical Center, Moreno Valley, California, USA
\end{abstract}

Correspondence to Dr Allison E Berndtson, Department of Surgery, University of California San Diego Health System, San Diego CA 92103, USA; aberndtson@ ucsd.edu

Received 3 December 2018 Revised 18 January 2019 Accepted 9 February 2019

(C) Author(s) (or their employer(s)) 2019. Re-use permitted under CC BY-NC. No commercial re-use. See rights and permissions. Published by BMJ.

To cite: Berndtson $A E$,

Morna M, Debrah S, et al.

Trauma Surg Acute Care Open 2019;4:e000287.

\section{ABSTRACT}

Introduction Trauma and injury are significant contributors to the global burden of disease, with 5 million deaths and 250 million disability-adjusted life years lost in 2015. This burden is disproportionally borne by low- and middle-income countries (LMICs). Solutions are complex, but one area for improvement is basic trauma education. The American College of Surgeons has developed the Trauma Evaluation and Management (TEAM) course as an introduction to trauma care for medical students. We hypothesized that the TEAM course would be an effective educational program in LMICs and result in increased knowledge gains and retention similar to students in high-income countries (HICs).

Methods The TEAM course was taught and students evaluated at two sites, one LMIC (Ghana) and one HIC (USA), after obtaining approval from the HIC Institutional Review Board and medical schools at both sites. Participation was optional for all students and results were de-identified. The course was administered by a single educator for all sessions. Multiple-choice exams were given before and after the course, and again 6 months later.

Results A total of 62 LMIC and 64 HIC students participated in the course and completed initial testing. Demographics for the two groups were similar, as was participant attrition over time. LMIC students started with a relative knowledge deficit, scoring lower on both pre-course and post-course tests than HIC students, but gained more knowledge during the initial teaching session. After 6 months, the LMIC students continued to improve, whereas the HIC students' knowledge had regressed. Most students recommended course expansion.

Conclusion The TEAM course is a useful tool to provide the basic principles of trauma care to students in LMICS, and should be expanded. Further study is needed to determine the impact of TEAM education on patient care in LMICs.

Level of evidence Level III; Care Management

\section{BACKGROUND}

Traumatic injury remains one of the most frequent causes of death and disability worldwide, constituting $10.1 \%$ of the global burden of disease in 2013. ${ }^{1}$ This burden is disproportionately borne by low/middle-income countries (LMICs), where resources for advances in care are limited despite estimates that improved care could save up to 2 million lives annually. ${ }^{2}$ While the limitations on providing excellent trauma care are multifactorial, education of providers has been proven to improve patient outcomes, ${ }^{3}$ and a lack of training has been identified as the most common limitation after the lack of equipment itself. ${ }^{4}$

Advanced trauma life support (ATLS) has become the standard training course for trauma care in the USA, and has also been taught effectively both in ${ }^{5}$ LMICs and to medical student trainees. ${ }^{6}$ ATLS is both labor-intensive and costly however, ${ }^{7}$ limiting its utility in both settings. These concerns led the American College of Surgeons Committee on Trauma (ACS COT) to develop the Trauma Evaluation and Management (TEAM) program, a shorter version of ATLS intended as an introduction to trauma care for medical students. TEAM has been successfully taught to students throughout the USA and Canada as well as in LMICs. ${ }^{8-11}$

Although TEAM has been shown to improve trauma education worldwide, to our knowledge no studies thus far have evaluated and compared knowledge retention between students in high-income countries (HICs) and LMICs. We hypothesized that students from HICs and LMICs would show similar knowledge gains and retention from the TEAM course.

\section{METHODS}

Students from the USA and Ghana were chosen to represent HICs and LMICs. The TEAM course was introduced at the University of Cape Coast, Ghana in November of 2015, where it was taught to sixth (senior)-year medical students. Each student was provided with a copy of the TEAM manual at the time of the course; these books were provided free of charge by the ACS. An 18-question multiple-choice cognitive exam also written by the ACS Committee on Trauma was administered to the students both immediately before and after the course, to evaluate baseline knowledge and gains from the course itself. A subset of these students were also able to complete a 6-month follow-up exam to evaluate knowledge retention. The same test was used for each evaluation as this is what was provided by the ACS COT, and the testing of the students was approved by the University of Cape Coast Department of Surgery as a part of their standard trauma curriculum. The course and testing were repeated again in 2017 for that year's senior students.

For US students, the course and testing were started in January 2016. The course is taught approximately monthly to small groups of 
Table 2 Pre-course, post-course and 6-month follow-up test scores by country

\begin{tabular}{llll}
\hline & Pre-test $^{*}$ & Post-test $^{*}$ & 6-month test* \\
\hline Ghana & $44.2 \pm 11.5$ & $69.1 \pm 11.5 \dagger$ & $81.6 \pm 7.3 \dagger$ \\
USA & $60.4 \pm 12.5$ & $77.6 \pm 12.4 \dagger$ & $66.1 \pm 10.8$ \\
\hline
\end{tabular}

Mean \% correct, \pm SD

*Significant difference between countries $(p<0.05)$.

†Significant difference from pre-test $(p<0.05)$

third-year medical students and fourth-year sub-interns as they rotate through the Trauma, Burns, Acute Care Surgery or Surgical Intensive Care Unit services at the University of California-San Diego. The same pre-test, post-test and 6-month exam was used as for the Ghanaian students. The students again received their textbooks the day of the course, and books are paid for by the Division of Trauma, Surgical Critical Care, Burns and Acute Care Surgery. For the US students, the testing was deemed Exempt from Approval by the University of California-San Diego Institutional Review Board, and was approved by the Dean of Student Affairs with the restriction that completion of testing must be optional for students and all results be de-identified. These same restrictions were subsequently added to the Ghana student's exams for parity.

All tested courses were taught by the same instructor (AEB). Each exam also included a series of non-clinical questions: the additional pre-test questions evaluated student demographics, whereas the post-test survey sought student perceptions of the course on a scale of $1-5(1=$ strongly disagree, $5=$ strongly agree) as well as perceived barriers to utilizing new knowledge (free-text response). The free-text responses were reviewed and categorized into themes; the prevalence of each theme was then compared between groups. Unpaired t-tests were used for comparing the pre-test, post-test and 6-month follow-up results within the groups, as well as for comparing each testing time between groups. A p value $<0.05$ was considered statistically significant.

\section{RESULTS}

A total of 62 Ghana and 64 US students took both the TEAM course and the pre-course test for evaluation of baseline knowledge. Ghana students were slightly younger than US students $(25.3 \pm 3.0$ years vs $26.7 \pm 3.5$ years, $\mathrm{p}=0.017)$, but there was no significant difference in reported gender $(50 \%$ female Ghana vs $39.7 \%$ female USA, $\mathrm{p}=0.25$; table 1 ). US students performed significantly better on the pre-course test than Ghana students (mean \pm SD $44.2 \% \pm 11.5 \%$ correct Ghana vs $60.4 \% \pm 12.5 \%$ for USA, $\mathrm{p}<0.001$; table 2). The post-course test was taken by 54 Ghana and 50 US students. Post-test scores improved significantly for both groups, up to $69.1 \% \pm 11.5 \%$ correct for Ghana students and $77.6 \% \pm 12.4 \%$ correct for US students (vs pre-test, $\mathrm{p}<0.001$ for each), though scores remained significantly

\begin{tabular}{lll}
\hline \multicolumn{3}{l}{ Table 1 Demographics by country. } \\
\hline & Ghana & USA \\
\hline Age (years, mean \pm SD) & $25.3 \pm 3.0$ & $26.7 \pm 3.5^{*}$ \\
\% Female & $50 \%$ & $39.7 \%$ \\
Students taking: & $\mathrm{N}$ & $\mathrm{N}$ \\
\multicolumn{1}{c}{ Pre-test } & 62 & 64 \\
Post-test & 54 & 50 \\
6-month test & 13 & 19 \\
\hline
\end{tabular}

*Significant difference between countries $(p<0.05)$.
Ghana vs. USA TEAM Scores

100

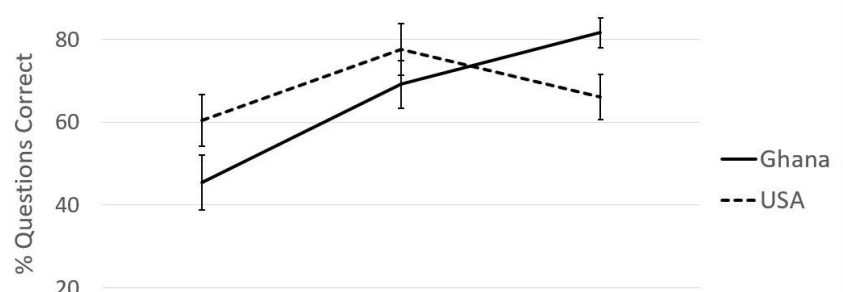

0

$$
\text { PreTest } \quad \text { PostTest } 6 \text { Months }
$$

Figure 1 Pre-course, post-course and 6-month follow-up test scores, by country (mean \pm SD).

different between groups $(\mathrm{p}<0.001)$. The 6-month follow-up exam was taken by 13 Ghana and 19 US students. Ghana students' scores continued to improve, to $81.6 \% \pm 7.3 \%$ of questions correct ( $\mathrm{p}<0.001$ vs post-test), whereas US students saw a drop in their mean score to $66.1 \% \pm 10.8 \%$ ( $\mathrm{p}<0.001$ vs posttest), performing significantly worse than the Ghana students $(p<0.001$ between countries; figure 1). The 6-month score for US students was no longer statistically significantly different than their pre-test score $(\mathrm{p}=0.079)$.

The post-test survey included six questions designed to assess what students thought of the TEAM course, with each response graded from 1 to 5 (Strongly Disagree, Disagree, Neutral, Agree and Strongly Agree). In all, 37 Ghana and 46 US students completed the post-test survey questions (table 3). Greater than $90 \%$ of students in both groups answered Agree or Strongly Agree to all questions except 'I gained new knowledge about mass casualty situations'. 100\% of Ghana and $95.7 \%$ of US students indicated that they would recommend the course to colleagues.

The post-test survey also asked students 'What are the barriers to using or implementing what you have learned?' with room for a free-text response. Many students cited multiple possible barriers, with 22 Ghana students providing 38 comments while 44 US students gave a total of 46 responses. Ghana students were most likely to cite barriers involving infrastructure and teamwork issues (18 of 38 comments or $47.4 \%$ ) or lack of physical equipment (39.5\%) (figure 2). Sample comments include 'Inadequacy of resources in this part of the world', 'Few equipments (ie, no laryngoscope, endotracheal tube (ETT) or ventilator in Accident \& Emergency (A\&E))', 'Lack of effective ambulance services' and 'Lack of trained personnel in the TEAM approach

Table 3 Post-test survey: percentage of students rating each statement Agree or Strongly Agree, by country

\begin{tabular}{lcc}
\hline & $\begin{array}{c}\text { Ghana } \\
\text { (N=37) }\end{array}$ & $\begin{array}{l}\text { USA } \\
\text { (N=46) }\end{array}$ \\
\hline $\begin{array}{l}\text { I gained new knowledge about the evaluation and care } \\
\text { of injured patients }\end{array}$ & $97.3 \%$ & $95.5 \%$ \\
\hline I gained new knowledge about mass casualty situations & $86.5 \%$ & $82.6 \%$ \\
\hline I am better prepared to care for injured patients & $97.2 \%$ & $91.3 \%$ \\
\hline I feel this course is appropriate for my level of training & $97.3 \%$ & $95.7 \%$ \\
I am satisfied with what I learnt & $100 \%$ & $97.8 \%$ \\
\hline I would recommend this course to colleagues & $100 \%$ & $95.7 \%$ \\
\hline
\end{tabular}




\section{Perceived Barriers to Knowledge Implementation}

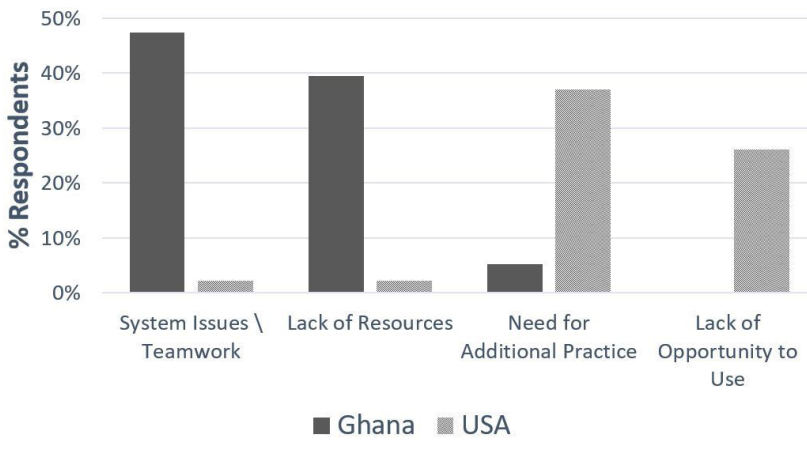

Figure 2 Perceived barriers to implementation of new knowledge, by country.

because a multidisciplinary team is required for it to be efficient'. Several comments referenced the course not being available to all providers or inadequate training of nurses and pre-hospital personnel. Only two students each cited lack of practice or no barriers to implementation. In contrast, US students were most likely to see a lack of practice $(37.0 \%)$ or the opportunity to actually care for patients with trauma $(26.1 \%)$ as potential barriers, though comments were less uniform. Sample comments describing barriers included 'Experience in identifying physical signs related to injury and going through primary and secondary surveys', 'Not feeling fully qualified', 'I'm not in an environment where I'd be running a trauma' and 'If I pursued a specialty that didn't interact with trauma regularly'. Seven students identified no barriers while only one each referenced lack of resources or issues with teamwork.

\section{DISCUSSION}

Students from the USA and Ghana both demonstrated significant knowledge gains after the TEAM course; however, only Ghana students retained this knowledge at 6 months, counter to our hypothesis. The immediate effect of the TEAM course on trauma knowledge has been shown in multiple prior studies, with the course benefitting students from locations as diverse as the USA, ${ }^{12}$ Canada, ${ }^{8}$ Australia, ${ }^{13}$ Mexico, ${ }^{14}$ Jamaica, Trinidad, Costa Rica and the United Arab Emirates. ${ }^{9}$ Knowledge retention, however, has been poorly studied to date-we could not find any prior studies comparing pre-course to longer-term knowledge in medical students. Li et $a l^{15}$ do evaluate comparative knowledge retention in senior medical students who took the course as juniors (11-23 months earlier); however, they compare the standard 2-hour TEAM lecture to a unique expanded (eTEAM) course of their own design rather than to pre-course knowledge. Their findings that students exposed to the eTEAM course perform better on specific aspects of the follow-up structured clinical examination is relevant however, as we theorize that the difference in USA and Ghana students at 6 months is partially explained by ongoing exposure to patients with trauma and the opportunity to use learned resuscitation skills.

Like many other cognitive and procedural skills, trauma knowledge and the ability to run a well-organized resuscitation may be affected by ongoing skill use. Ali et al have shown progressive attrition of trauma knowledge in physicians with less ongoing trauma exposure, ${ }^{16}$ whereas Fisher et al demonstrated degradation of unused complex clinical skills among medical students over time. ${ }^{17} \mathrm{~A}$ recent study by Mackenzie et al ${ }^{18}$ compared long-term retention of trauma procedural competency after the
Advanced Surgical Skills for Exposure in Trauma course, finding that practicing surgeons with infrequent interval opportunities to use the learnt skills made more errors on follow-up testing than either in-training residents or subject matter experts. They concluded that skill degradation was more strongly associated with lack of interval practice than time since training. There is even some data that trauma volume correlates with patient outcomes, leading to requirements that trauma centers meet a minimum number of admissions per year in order to qualify for ACS verification. ${ }^{19}$ We theorize that the higher level of knowledge retention in students from Ghana is directly correlated to both their increased exposure to trauma care and their anticipated future practice. Ghanaian students were taught during their final year of medical school, which consists of 6 months each of surgery and medicine. The surgical service covers all aspects of surgical care, including trauma, leading to frequent immersion in trauma education and skills practice. This is in contrast to US students, most of whom were taught during their MS3 year where only 8 weeks are spent on surgery and the rest on other specialties which often contain no exposure to patients with trauma.

Education is also more effective when knowledge is personally relevant-Ghanaian students all go on to a required period of general medical practice after graduation before being allowed to subspecialty train, whereas US students move straight into specialties and may never care for patients with trauma in their career, as was highlighted in several free-text comments. Given findings by Mock et al that a large volume of trauma care in Ghana is provided in smaller district hospitals by non-surgeon general practitioners, this education is highly relevant to all medical students in Ghana. ${ }^{20}$

Assessment of the students' perceived barriers to implementing their new knowledge raises several interesting questions in addition to corroborating some of the above theories. Students' freetext responses were characterized into themes, with significant differences in the frequency that each was cited between countries. Ghana students tended to focus on external limitations, such as a lack of physical equipment (oxygen or endotracheal tubes), lack of a trauma system (triage, prehospital services and communication) or lack of teammate education (nurses and medics). Only four comments out of the 38 provided cited other barriers-two remarking on the need for further practice and two who saw no barriers to utilizing their new skills. This is in stark contrast to US students who reported a lack of resources or lack of teamwork only once each out of 46 total comments. US students tended to report more internal limitations, with the most frequent potential barriers being either the need for further personal practice or no opportunity to use their skills, obstacles that directly relate to our proposed theory of ongoing skill usage above.

Overall the course was well received, though Ghana students rated the course more positively than US students in all categories. The only question receiving a less than 90\% approval rating was regarding new knowledge about mass casualty situations, which is a very limited section of the standard TEAM course. Greater than $95 \%$ of students in both groups, and $100 \%$ of Ghana students, indicated that they were satisfied with what they had learnt and would recommend the course to colleagues. Our findings regarding perceptions of the course are in line with previous studies, which also indicate a high level of student appreciation for further trauma education, particularly in LMICs. ${ }^{8-11} 21$

Our study does have limitations. Our participant attrition was higher than expected, with fewer students taking the post-course 
and 6-month exams than the pre-course test. Approval of this project by the University of California San Diego School of Medicine required that all testing be optional for students, and their results completely de-identified; we applied the same criteria to Ghanaian students to reduce bias that may have arisen if some students were required to take the exam and others were not. This requirement did limit student participation particularly at the 6-month mark, as well as made it impossible to track individual knowledge retention or correlate scores with USA student career interests. There is still a potential for bias in that students more interested in trauma may have been more likely to take the follow-up exams; however, this was likely mitigated by the similar level of attrition between the two groups. We also used the same 18 questions for the pre-test, post-test and 6-month follow-up exams as this is what was provided by the ACS COT; using different sets of questions of a similar difficulty may have been a better test of true knowledge gain, however. Our project only tested cognitive knowledge on a multiple-choice exam rather than assessing clinical applicability or results-we did not assess any improvements in patient outcomes. Studies such as those by Petroze $e^{2} a^{22}$ provide some data that focused trauma education can improve outcomes, but further research will be required to demonstrate this definitively. Finally, a large proportion of trauma care in LMICs is often administered by non-physician providers in rural clinics; ${ }^{20}$ while medical students are an appropriate target for TEAM the course may require significant expansion to non-physicians to truly improve patient care.

In conclusion, the TEAM course improves cognitive trauma knowledge among medical students in both the USA and Ghana, but this knowledge is retained at 6 months only in Ghana students. The TEAM course is a useful tool to provide the basic principles of trauma care to students in LMICs, and should be expanded. Further study is needed to determine the impact of TEAM education on patient outcomes.

Acknowledgements Thank you to the students at both sites who participated in the TEAM course, as well as the University of Cape Coast Department of Surgery and University of California-San Diego School of Medicine and Division of Trauma, Surgical Critical Care, Burns and Acute Care Surgery for their support.

Contributors All authors made significant contributions to the completion of this project, and have had input in the final article submission. AEB: Study inception and design, data collection and analysis, creating tables and figures, drafting and critical revisions of the article. MM: Data collection, drafting and critical revisions of the article. SD: Data collection, critical revisions of the article. RC: Study inception and design, drafting and critical revisions of the article.

Funding The authors have not declared a specific grant for this research from any funding agency in the public, commercial or not-for-profit sectors.

Competing interests None declared.

Patient consent Not required.

Provenance and peer review Not commissioned; externally peer reviewed.

Open access This is an open access article distributed in accordance with the Creative Commons Attribution Non Commercial (CC BY-NC 4.0) license, which permits others to distribute, remix, adapt, build upon this work non-commercially, and license their derivative works on different terms, provided the original work is properly cited, appropriate credit is given, any changes made indicated, and the use is non-commercial. See: http://creativecommons.org/licenses/by-nc/4.0

\section{REFERENCES}

1. Haagsma JA, Graetz N, Bolliger I, Naghavi M, Higashi H, Mullany EC, Abera SF, Abraham JP, Adofo K, Alsharif U, et al. The global burden of injury: incidence, mortality, disability-adjusted life years and time trends from the global burden of Disease Study 2013. Inj Prev 2016:22:3-18.

2. Mock C, Joshipura M, Arreola-Risa C, Quansah R. An estimate of the number of lives that could be saved through improvements in trauma care globally. World J Surg 2012;36:959-63.

3. Collicott PE, Hughes I. Training in advanced trauma life support. JAMA 1980:243:1156-9.

4. Stewart BT, Quansah R, Gyedu A, Boakye G, Abantanga F, Ankomah J, Donkor P, Mock C. Serial assessment of trauma care capacity in Ghana in 2004 and 2014. JAMA Surg 2016;151:164-71.

5. Ali J, Adam R, Butler AK, Chang H, Howard M, Gonsalves D, Pitt-Miller P, Stedman M, Winn J, Williams Jl, et al. Trauma outcome improves following the advanced trauma life support program in a developing country. J Trauma 1993;34:890-9. discussion 98-9.

6. Ali J, Cohen RJ, Gana TJ, Al-Bedah KF. Effect of the advanced trauma life support program on medical students' performance in simulated trauma patient management. J Trauma 1998;44:588-91.

7. World Health Organization. Guidelines for essential trauma care: World Health Organization, 2004

8. Ali J. The trauma evaluation and management (team) teaching module: its role for senior medical students in Canada. Can J Surg 2003;46:99-102.

9. Ali J, Cherry RA, Williams JI. Trauma base knowledge and the effect of the trauma evaluation and management program among senior medical students in seven countries. J Trauma 2005;59:43-8.

10. Ali J, McDonald A, Newnham M. Improving medical undergraduate trauma education through the trauma evaluation and management programme at mona. West Indian Med J 2003:52:45-8.

11. Kurdin A, Caines A, Boone D, Furey A. Team: a low-cost alternative to ATLS for providing trauma care teaching in Haiti. J Surg Educ 2018;75:377-82.

12. Cherry RA, Ali J, Williams JI. Trauma evaluation and management: who benefits among medical students? J Surg Res 2005:126:189-92.

13. Ali J, Danne P, McColl G. Assessment of the trauma evaluation and management (team) module in Australia. Injury 2004;35:753-8.

14. Delgado-Reyes L, Gasca-González 00, Delgado-Guerrero F, Reyes-Arellano W. [Effectiveness of Trauma Evaluation and Management course for Mexican senior medical students: When to implement it?]. Cir Cir 2016:84:220-4.

15. Li MS, Brasel KJ, Schultz D, Falimirski ME, Stafford RE, Somberg LB, Weigelt JA. Effective retention of primary survey skills by medical students after participation in an expanded trauma evaluation and management course. Am J Surg 2006;191:276-80.

16. Ali J, Howard M, Williams J. Is attrition of advanced trauma life support acquired skills affected by trauma patient volume? Am J Surg 2002;183:142-5.

17. Fisher J, Viscusi R, Ratesic A, Johnstone C, Kelley R, Tegethoff AM, Bates J, Situ-Lacasse EH, Adamas-Rappaport WJ, Amini R, et al. Clinical skills temporal degradation assessment in undergraduate medical education. J Adv Med Educ Prof 2018;6:1-5.

18. Mackenzie CF, Bowyer MW, Henry S, Tisherman SA, Puche A, Chen H, Shalin V, Pugh K, Garofalo E, Shackelford SA, et al. Cadaver-Based Trauma Procedural Skills Training: Skills Retention 30 Months after Training among Practicing Surgeons in Comparison to Experts or More Recently Trained Residents. J Am Coll Surg 2018;227(2):270-9.

19. American College of Surgeons. Resources for optimal care of the injured patient. Chicago: American College of Surgeons, 2014.

20. Mock C, Ofosu A, Gish O. Utilization of district health services by injured persons in a rural area of Ghana. Int J Health Plann Manage 2001;16:19-32.

21. Ali J, Adam R, Williams JI, Bedaysie H, Pierre I, Josa D, Winn J. Teaching effectiveness of the trauma evaluation and management module for senior medical students. J Trauma 2002;52:847-51.

22. Petroze RT, Byiringiro JC, Ntakiyiruta G, Briggs SM, Deckelbaum DL, Razek T, Riviello R, Kyamanywa P, Reid J, Sawyer RG, et al. Can focused trauma education initiatives reduce mortality or improve resource utilization in a low-resource setting? World J Surg 2015;39:926-33. 